Revue d'histoire de l'Amérique française

REVUE D.HISTOIRE DE L'AMÉRIQUE FRANÇAISE

\title{
Le fondateur de la Société des Écrivains canadiens
}

Jean Bruchési

Volume 22, numéro 3, décembre 1968

URI : https://id.erudit.org/iderudit/302820ar

DOI : https://doi.org/10.7202/302820ar

Aller au sommaire du numéro

Éditeur(s)

Institut d'histoire de l'Amérique française

ISSN

0035-2357 (imprimé)

1492-1383 (numérique)

Découvrir la revue

Citer ce document

Bruchési, J. (1968). Le fondateur de la Société des Écrivains canadiens. Revue

d'histoire de l'Amérique française, 22(3), 489-490.

https://doi.org/10.7202/302820ar d'utilisation que vous pouvez consulter en ligne.

https://apropos.erudit.org/fr/usagers/politique-dutilisation/ 


\section{Le fondateur de la Société des Ecrivains canadiens}

Dans un compte rendu du volume Survol de la littérature canadienne-française de Paul Gay, paru dans notre RHAF, vol. XXI : 835-836, M. Roger Duhamel écrivait: "Si mon souvenir est fidèle, c'est $M$. Victor Barbeau, et non pas $M$. Jean Bruchési, qui est le fondateur de la Société des Ecrivains canadiens. La confusion s'explique aisément. M. Bruchési fut bien le président de la section française de la Canadian Authors' Association, d'où procéderait quelques années plus tard, à l'instigation de M. Barbeau, la Société des Ecrivains. Par la suite, il est vrai que M. Bruchési assuma avec brio et efficacité la présidence de la Société des Ecrivains qu'avait abandonnée M. Barbeau. Détail minime, bien sûr, mais il faut toujours serrer de plus près possible la vérité historique."

Aux mêmes fins de "serrer de plus près possible la vérité historique", la Revue qui ne devient pas pour autant un bulletin de recherches historiques, consent à publier la mise au point suivante de M. Jean Bruchési. C'est un extrait d'une lettre que ce dernier adressait à $M$. Roger Duhamel en mai dernier.

"Oui, je fus bien le président de la section française de la “Canadian Authors' Association". J'avais accepté le poste, entre 1931 et 1936, dans l'espoir d'être utile et avec l'intention de mettre sur pied le plus tôt possible une société d'écrivains canadiens-français. Ainsi, la collaboration - ce fut toujours mon idéal - se ferait entre les têtes ou par la tête. Mon intention se précisa avec le temps, surtout grâce aux attaques souriantes de Louis Francœur qui, à ma demande, refusa carrément d'adhérer à la "sous-section" française de la "Canadian Authors' Association", comme il aimait à le répéter sur tous les tons. Et, un jour, je lui posai carrément la question: "Ferez-vous partie - et 
activement - d'une société autonome qui groupera les écrivains canadiens-français ? J'ai résolu d'en fonder une." Francœur ne s'engagea point trop avant, car il se réservait d'aimer ou de ne pas aimer certains des futurs membres. C'est alors qu'Albert Lévesque et moi rédigeâmes un premier projet de constitution qui fut discuté au cours d'une réunion d'écrivains canadiensfrançais; et j'avais pris soin de prévenir mes "collègues" de la "Canadian Author's Association" de ce qui allait se produire. Dans l'intervalle - c'était en février ou mars 1937 - on m'avait offert le poste de sous-secrétaire de la Province, mais il m'était interdit d'en souffler mot. J'ai quand même poursuivi l'étude du projet, sachant bien que j'aurais à recevoir la requête des intéressés et à émettre les "lettres-patentes". Je ne pouvais donc être au nombre des requérants, encore moins accepter la première présidence de la nouvelle société. C'est moi qui ai proposé Victor Barbeau, lui laissant le soin, ainsi qu'à Albert Lévesque et, je crois, à Mgr Olivier Maurault, de présenter la requête à Québec et de rédiger les règlements comme l'exigeait la troisième partie de la Loi des Compagnies.

Telle est, mon cher ami, la vérité toute nue... Et c'est toujours ce que j'ai dit lorsqu'on m'a questionné sur l'événement. Le projet d'une société d'écrivains canadiens-français est venu d'abord de votre humble serviteur et je me suis mis au blanc le premier, comme j'ai, le premier, mis la main à la pâte. Les circonstances ont voulu que je cède le devant de la scène à un autre lorsque l'enfant a été mis au monde et porté au baptême par d'autres que le père véritable, ou putatif si vous le préférez. Mais le germe qui a rendu la naissance possible n'a pas été produit par un autre que moi. Au demeurant, chaque fois que j'en ai eu l'occasion, je n'ai jamais omis d'adjoindre, à la fondation légale de la Société des Ecrivains, Albert Lévesque et surtout Victor Barbeau."

JEAN BRUCHÉSI 